\title{
LITERATURA DIGITAL NA SALA DE AULA: UMA PROPOSTA DIDÁTICA COM O HIPERCONTO MULTISSEMIÓTICO
}

\author{
DIGITAL LITERATURE IN CLASSROOM: A DIDACTIC \\ PROPOSAL WITH THE MULTI-SEMI-HYPOTHIC HYPERTONE
}

\author{
Fernanda Karyne de Oliveira* \\ Simone Dália de Gusmão Aranha**
}

\begin{abstract}
Resumo: Atualmente, vivemos em um cenário delineado pelo desenvolvimento de tecnologias, mas especificamente, das tecnologias digitais da informação e da comunicação (TDIC). Nesse contexto, não somente houve mudanças na circulação de informações, mas também no modo como os indivíduos se relacionam e, por extensão, no modo como o processo ensino-aprendizagem se desenvolve no espaço escolar. Frente a tais mudanças propiciadas por esse paradigma tecnológico e, considerando a necessidade de se atualizar para atender às demandas vigentes, a escola deve repensar suas práticas, vislumbrando ações pedagógicas que possibilitem aos alunos a capacidade de atuar nesse novo tempo, marcado pelas tecnologias digitais. Este artigo objetiva apresentar uma proposta didática com um gênero literário do meio digital, denominado Hiperconto Multissemiótico, por Spalding (2009). Este estudo baseia-se em teóricos como Soares (2002, 2012), Rojo (2012, 2013, 2015), Cosson (2006, 2014), entre outros.
\end{abstract}

Palavras-chave: Literatura digital. Proposta didática. Leitura e Escrita. Hiperconto Multissemiótico.

Abstract: Currently, we live in a scenario outlined by the development of technologies, but specifically, Digital Information and Communication Technologies. In this context, not only have there been changes in the circulation of information, more also in the way in which individuals relate and, by extension, in the way the teaching-learning process takes place in the school space. Faced with such changes brought about by this technological paradigm, and considering the need to update to meet current demands, the school must rethink its practices, envisaging pedagogical actions that enable students to act in this new time, marked by digital technologies. This article aims to present a didactic proposal with a literary genre of the digital medium, called Multisemiotic Hiperconto, by Spalding (2009). This study is based on theoreticians such as Soares (2002, 2012), Rojo (2012, 2013, 2015), Cosson (2006, 2014), among others.

Keywords: Digital literature. Didactic proposal. Reading and writing. Multisemiotic hypercont.

\section{Introdução}

Em virtude das crescentes mudanças na sociedade atual, sobretudo, pela forma e velocidade com que circulam as informações, delineia-se um cenário de desenvolvimento constante de tecnologias digitais e em rede. Neste contexto, é importante destacarmos que na produção e circulação de textos, as redes sociais digitais funcionam como domínios heterogêneos, agregando vários gêneros textuais, entre esses, gêneros do campo da literatura.

Dentre os principais compromissos da instituição escolar, a formação de leitores e escritores proficientes apresenta-se como imprescindível. Desta maneira, é papel da escola formar sujeitos que sejam capazes de refletir "sobre seu papel no mundo, (...) a partir do saber fazer, do saber ler, do saber se portar, se posicionar e

\footnotetext{
* Mestranda no Programa de Pós-Graduação em Formação de Professores, da Universidade Estadual da Paraíba, campus I, pela linha de pesquisa "Linguagens, Culturas, Formação Docente". Graduada em Letras, com habilitação em Língua Portuguesa, pela UEPB/Campus I. fernandakoliveira@gmail.com

** Doutora em Letras pela Universidade Federal da Paraíba. Professora Associada da Universidade Estadual da Paraíba, Departamento de Letras e Artes. Coordenadora do Mestrado em Formação de Professores da Universidade Estadual da Paraíba, Campus I. simonedga@ hotmail.com
} 
defender seu ponto de vista diante de outro, (...) seja no contexto familiar, na comunidade onde atua na escola, nos vários espaços por onde transita" (SILVA, 2016, p.59). Para tanto, é necessário trazermos para o espaço escolar, culturas em que os jovens estejam inseridos, levando em conta os seus saberes e as suas experiências pessoais, a exemplo das redes sociais digitais, espaços contemporâneos nos quais inúmeras dessas experiências são vivenciadas e compartilhadas.

Assim, esse novo cenário proposto pelas Tecnologias Digitais da Informação e Comunicação (TDIC), favorecido pela disseminação e intensificação do uso das Redes sociais Interativas (RSI), influenciou não somente as interações sociais, mas também os modos de ler e escrever, como afirma Chartier (1998), ao dizer que não foram somente os gestos que mudaram, mas também os objetos lidos e as formas de ler esses objetos: novas atitudes são empreendidas, ao passo que outras desaparecem com o passar do tempo.

As mudanças e ressignificações mencionadas anteriormente, no que diz respeito à leitura e à escrita, também afetaram o campo da literatura. Na ótica de Silva (2016), a literatura atual demanda do leitor novos parâmetros de leitura para as formas literárias e os novos gêneros textuais que estão emergindo, destacando que é preciso que haja uma flexibilização quanto aos modos de conceber o que é produzido na contemporaneidade, desprendendo-se de olhares preconceituosos, olhares estes que ameaçam o processo de formação leitora. É preciso, pois, ter em mente que cada ato de leitura é diferente e, consequentemente, requer que o texto seja abordado de forma diferente. Além disso, cada leitura traz seus próprios objetivos, sua motivação, seus interesses, ideias e experiências, como defende Coscarelli (2016).

Diante desse panorama de inovações tecnológicas, destacamos a literatura digital, entendida, aqui, como a literatura que tira proveito das potencialidades do ciberespaço no processo de criação de seus textos, sendo, portanto, marcadamente interativa. Alguns gêneros textuais presentes no meio virtual são próprios deste tipo de literatura, a exemplo do Hiperconto Multissemiótico, termo cunhado por Spalding (2009). Sobre o gênero em questão, o autor explica que o denominou Hiperconto Multissemiótico pelo fato de se tratar de um conto advindo da era digital, utilizando ferramentas tecnológicas para potencializar a sua narrativa. Assim, apoiados em Santaella (apud SIGNORINI, 2008), consideramos o Hiperconto Multissemiótico como um hipertexto, tendo em vista que este é construído a partir da interatividade entre o leitor e o texto digital, o que permite diferentes percursos de leitura, além da criação de novas histórias, mediante a escolha dos links que podem ou não ser clicados

Para Robin (2016), o hipertexto se inscreve numa era em que a complexidade, a multiplicidade, a heterogeneidade, o aleatório, a instabilidade, a fragmentação, a redefinição de nosso meio ambiente e de nossas identidades reinam em nossa vida cotidiana. Mediante a isto, e considerando o espaço cedido para o trabalho com a literatura digital em sala de aula, o Hiperconto Multissemiótico configura-se como uma alternativa de incentivo à leitura literária, propiciando também diálogos com as narrativas clássicas, partindo do pressuposto de que "é papel do professor partir daquilo que o aluno já conhece para aquilo que ele desconhece, a fim de se proporcionar o crescimento do leitor por meio da ampliação dos seus horizontes de leitura" (COSSON, 2006, p.35).

Nesta tentativa de aproximação da realidade do aluno com gêneros textuais do campo literário, que se encontram presentes no meio digital, o presente artigo visa apresentar uma proposta didática para o trabalho com o gênero Hiperconto Multissemiótico em sala de aula, à luz dos pressupostos teóricos de Cosson (2006, 
2014), Spaldin (2009, 2012), Chartier (1998, 2002), Kleiman (1995), Soares (2002, 2012), Rojo (2012, 2013, 2015), entre outros.

\section{Sobre letramento(s)}

Na sociedade contemporânea, o trabalho com gêneros textuais emergentes do ambiente virtual desafia professores, pois, além de exigir novas habilidades e competências desses profissionais, também acarreta o uso de vários tipos de letramentos. Nesse sentido, a proposta que será aqui apresentada utilizando o hiperconto (gênero emergente do ambiente virtual), contempla outros tipos de letramento, além do letramento literário, tais como o letramento digital e os multiletramentos.

Em meados dos anos 80, a palavra Letramento surge em estudos das áreas da Educação e das Ciências Linguísticas e, desde então, tem se tornado cada vez mais frequente nas reflexões desses especialistas.

É relevante destacar que o significado do termo letramento, que utilizamos hoje no Brasil, surgiu a partir da palavra literacy, originária do latim littera (letra) com o acréscimo do sufixo - cy, denotando "o estado ou condição que assume aquele que aprende a ler e escrever", conforme afirma Soares (2012, p.17). Nesse contexto, esse termo foi empregado como resultado da ação de um grupo ou de determinado indivíduo em se apropriar do ato de ler e de escrever para, através dessa ação, alterar as suas práticas sociais cotidianas. Em outras palavras, o fenômeno do letramento passa a ser entendido "como um conjunto de práticas sociais que usam a escrita, como sistema simbólico e como tecnologia, em contextos específicos, para objetivos específicos" (KLEIMAN, 1995, p. 18-19).

Devido ao fato de, muitas vezes, a palavra letramento ter sido posta em relação dicotômica com o conceito de alfabetização, - na tentativa de separar os estudos sobre a alfabetização (o ato de decodificação do código escrito) daqueles que examinam os impactos sociais dos usos da escrita-, veio à tona outra perspectiva, na qual o conceito de letramento:

(...) começou a ser usado nos meios acadêmicos numa tentativa de separar os estudos sobre o 'impacto social da escrita' dos estudos sobre a alfabetização, cujas conotações escolares destacam as competências individuais no uso e na prática da escrita. (KLEIMAN, 1995, p. 15)

Na obra Novas práticas de leitura e escrita: letramento na cibercultura, Soares (2002) enfatiza que existem diferentes modalidades de letramento e sugere que a palavra seja pluralizada, ou seja, há letramentos e não letramento: "diferentes espaços de escritas e diferentes mecanismos de produção". É nessa perspectiva, confrontando tecnologias digitais de leitura e de escrita com tecnologias tipográficas, que essa autora sugere o uso do sintagma "letramento digital" para referir-se às práticas de leitura e de escrita mediadas pelo uso do computador e da internet.

No que se refere ao conceito de letramento digital, Buzato (2006, p. 16), o entende como um caso paradigmático dos "novos letramentos". Ele teoriza que esse letramento corresponde às práticas sociais "que se apoiam, entrelaçam, e apropriam mútua e continuamente por meio de dispositivos digitais", tais como smartphones, iPads, notebooks, tablets e aparelhos de TV digitais - com finalidades específicas, sejam em contextos socioculturais limitados fisicamente ou em contextos online, e são construídos através da interação social mediada eletronicamente. 
No entanto, o letramento digital não corresponde apenas ao ato de saber manusear aparelhos eletrônicos: entre outras ações interativas, por exemplo, ele nos impulsiona a aprender a localizar e selecionar dados por meio de navegadores, hyperlinks e mecanismos de busca. Nesse sentido, esse tipo de letramento favorece a um conjunto de competências, através das quais o usuário passa a utilizar, de maneira crítica, os dados oriundos de múltiplas fontes e de diversos formatos, propagados cotidianamente pela internet.

Com o advento das tecnologias digitais em nossas atividades cotidianas, surge, pela primeira vez, o termo multiletramentos, por ocasião do Colóquio do Grupo de Nova Londres (GNL) ${ }^{*}$, no ano de 1996. Firmava-se, nessa época, o interesse em se trabalhar na sala de aula os novos letramentos, a diversidade cultural da população e a multiplicidade de linguagens que circulam dentro e fora do ambiente escolar:

O conceito de multiletramentos, articulado pelo Grupo de Nova Londres, busca justamente apontar, já de saída, por meio do prefixo "multi", para dois tipos de "múltiplos" que as práticas de letramento contemporâneas envolvem: por um lado, a multiplicidade de linguagens, semioses e mídias envolvidas na criação de significação para os textos multimodais contemporâneos e, por outro, a pluralidade e a diversidade cultural trazidas pelos autores/leitores contemporâneos a essa criação de significação. (ROJO, 2013, p.14)

$\mathrm{Na}$ visão desse Grupo, urge incluir os multiletramentos no currículo escolar, levando em conta a grande variedade de culturas já existentes nas salas de aula de um mundo globalizado. Para isso, faz-se necessário uma pedagogia dos multiletramentos, cujo conceito não aponta para a multiplicidade e variedade de práticas letradas, que são ou não valorizadas socialmente; no entanto,

(...) para dois tipos específicos e importantes de multiplicidade presentes em nossas sociedades, principalmente urbanas, na contemporaneidade: a multiplicidade cultural das populações e a multiplicidade semiótica de constituição dos textos por meio dos quais ela se informa e se comunica. (ROJO, 2012, p. 13)

É assim, pois, que concebemos o estudo de gêneros literários advindos do universo digital como "uma prática interdisciplinar de leitura em que a intertextualidade literária e cultural não pode ficar de lado nas interpretações contemporâneas" (GOMES, 2010, p.27). O foco da nossa proposta didática surge da necessidade de aproximação das culturas juvenis que vigoram no cotidiano escolar, possibilitando uma abordagem mais instigante e significativa para os alunos no tocante ao ensino-aprendizagem.

\section{Literatura digital: incorporação dos recursos tecnológicos na sala de aula}

A incorporação da cultura digital modificou a produção de gêneros textuais emergentes. Dessa forma, grande parte dos gêneros produzidos atualmente combinam

\footnotetext{
* Trata-se de um Grupo de pesquisadores dos fenômenos dos letramentos que, reunido em Nova Londres, em Connecticut (EUA), após uma semana de discussões, publicou um manifesto intitulado A Pedagogy of Multiliteraticies - Designing Social Futures ("Uma pedagogia dos multiletramentos - desenhando futuros sociais”). Fizeram parte desse grupo: Courtney Cazden, Bill Cope, Mary Kalantzis, Norman Fairclough, Jim Gee, Gunther Kress, Allan e Carmem Luke, Sara Michaels e Martin Nakata. (ROJO, 2012, p. 11).
} 
imagens estáticas e em movimento, cores, áudios, links ou gifs. Essa diversidade de semioses, além de ser produzida nas redes sociais digitais, é marcada, sobretudo, pela interatividade e pelo espírito colaborativo das redes:

O surgimento e ampliação de contínuos de acesso às tecnologias digitais da comunicação e da informação provocaram a intensificação vertiginosa e a diversificação da circulação da informação nos meios de comunicação analógicos e digitais, provocaram mudanças significativas nas maneiras de ler, produzir e fazer circular textos na sociedade (ROJO, 2013, p. 19).

Na visão de Rildo Cosson (2014, p. 15), "a literatura estaria em nossos dias experimentando uma nova forma de alargamento ao ser difundida em diferentes formatos e veículos, usualmente em composição com outras formações artísticas": a chamada literatura digital.

A produção de textos pertencente a esse vertente literária contemporânea passou a ser mais difundida no Brasil pelo professor e escritor Marcelo Spalding, em sua tese de doutorado. Esse pesquisador concebe a literatura digital como um "monstro esperançoso", haja vista que suas adaptações mutativas derivam, justamente, da incorporação dos recursos oferecidos pelo ciberespaço, bem como de todas as suas possibilidades (SPALDING, 2012).

Ainda sobre esse modo contemporâneo de se fazer literatura, outra autora afirma que literatura digital pode ser definida como:

um tipo de literatura que engloba um conjunto de características e de propriedades que configuram, com uma finalidade estética própria, um novo modo de entender o literário, desenhado a partir das possibilidades tecnológicas deixadas em aberto pela tecnologia digital. (MESTRE, 2017, p.87)

Essa literatura abriga textos de natureza estética variada, como as narrativas interativas (os hipercontos), em que não há somente leitores, mas sim "lautores", no dizer de Rojo (2013), ao referir-se a usuários que realizam, simultaneamente, as atividades de leitura e de escrita e que constroem seus próprios sentidos na internet.

Esses textos literários presentes no meio digital, muitas vezes, rompem com as lógicas estéticas "impostas" e configuram-se como construções locativas ciberespaciais, produtos do e para o meio cibernético e, como tal, com características próprias dele.

Por sua vez, a respeito dessa problemática, que envolve a construção dos textos literários da contemporaneidade,

é necessário abrir espaço para uma discussão em torno das "formas narrativas" do "gênero literário prosa", sobretudo do conto e do romance, visto que os antigos conceitos ou definições não suportam nem comportam a emergência de obras que logo são alocadas na camisa de força em que se tornaram os conceitos em discussão, servindo como base precisa de leitura e interpretação do gênero literário apenas quando o leitor estiver diante de textos que corroborem o ideal de conto e de romance idealizados pelos conceitos clássicos. (SILVA, 2016, p.24-25) 
No que diz respeito à reflexão sobre em que medida essa tecnologia intervém na lógica de funcionamento das linguagens e até que ponto as linguagens nos revelam outro modo de conviver com as tecnologias digitais, pesquisadores defendem que:

O que notamos na ambiência digital é que o significado das palavras não cabe mais somente nelas mesmas. Assim como, matematicamente, há um lado escuro do cubo, cuja existência não é invalidada por não conseguirmos vê-lo, a palavra, no meio digital, parece evocar problema parecido. Há um significado que não mais está ligado a um signo usual ou poético, mas sim a um signo que se mostra em expansão, dilatando-se. Ele, o significado, está lá, mas só é detectado pelos seus componentes binários, que, diga-se de passagem, estão entrelaçados aos componentes binários do som, da imagem e demais acontecimentos manifestados na tela do computador. (SALES e AZEVEDO, 2012, p.53)

Assim, a literatura digital "faz parte da vida desses jovens porque eles a produzem no ato da simulação, aparentemente vivenciando a narrativa ficcional de um modo muito mais intenso do que aquela tradicionalmente atribuída à leitura de um romance", de acordo com Cosson (2014, p.22).

Sobre este universo criado pela revolução na textualidade digital, é possível verificar que "é ao mesmo tempo uma revolução da modalidade técnica da produção do escrito, uma revolução da percepção das entidades textuais e uma revolução das estruturas e formas mais fundamentais dos suportes da cultura escrita", conforme bem argumenta o autor Chartier (2002, p.24). Essa revolução nas formas de textualidade se dá também pela própria alteração nos papeis protocolares de leitores e escritores.

É por isso que Rojo (2013) utiliza o termo "lautor", porque concebe que o leitor em rede constrói o seu próprio percurso de leitura, e é o responsável pela atualização, pela marcação de informações importantes, e, por produzir sentido. A própria característica da internet, que articula espaços de informação, concomitante a espaços de produção, promove além da negociação de significados, a possibilidade de construção destes.

A leitura do hipertexto exige novas habilidades, em que não basta somente ler, mas é preciso, principalmente, produzir, construir, estabelecer relações de sentidos. Na ambiência digital, o aluno leitor é um lautor, mas é também um flâuner, no sentido baudelairiano da palavra, como teoriza Robin (2016), por perambular "sem compromisso pela cidade", nesse caso particularmente, no texto digital. Essa metáfora torna-se oportuna se pensarmos que é justamente essa perambulação descompromissada (mas ainda assim objetiva) que permite os diferentes percursos de leitura e, consequentemente, o desenvolvimento de novas habilidades no que concerne ao ato de ler e, porque não dizer, de escrever textos.

Sob a ótica de Cosson (2014, p. 18), a literatura digital é marcada pela "interação, que aproxima o texto literário do jogo e da criação conjunta, apagando ou tornando menos nítidas as posições de leitor e autor, a construção textual em camadas superpostas e multimodais como resultado da exploração dos muitos recursos disponibilizados pelo meio digital", inaugurando, assim, um novo paradigma na escrita literária, no fazer literatura, haja vista que nessa metamorfose literária a palavra escrita não é vista com o único elemento potencializador, mas no suporte que se inserem os textos, os recursos multimodais utilizados: a própria estrutura empreendida, que se atualiza conforme as necessidades do meio. 


\section{0 uso da literatura digital na escola: como fazer?}

Apresentaremos, a seguir, uma proposta didática que foi elaborada para ser desenvolvida no Ensino Médio, mas optamos por não indicar, especificamente, uma série e nem um intervalo de tempo, pois partimos do pressuposto de que essa proposta possa ser adequada às realidades a que forem aplicadas na escola.

Considerando que as inovações tecnológicas "exigem" dos indivíduos novas formas de utilização da leitura e da escrita, a sugestão deste trabalho com um gênero literário digital foi estruturada em nove "momentos interativos", os quais enfatizam não só a leitura do Hiperconto Multissemiótico, mas também a produção de textos, como já dito anteriormente.

Esta proposta didática encontra-se fundamentada em Cosson (2006), ao esquematizar o trabalho com os gêneros literários em sequências (básica e expandida). A proposta de sequências, enfatizada pelo autor, visa sistematizar o trabalho com a literatura em sala de aula. Ainda que embasada em Cosson, a proposta apresentada, a seguir, possui adaptações, pois visa não só a promoção do letramento literário, mas também outros tipos de letramento, como o digital e os multiletramentos. Senão, vejamos:

QUADRO 1- PROPOSTA DIDÁTICA: O HIPERCONTO EM SALA DE AULA

\begin{tabular}{|c|c|}
\hline $1^{\circ}$ momento interativo & $\begin{array}{l}\text { - Discussão inicial sobre redes sociais digitais, } \\
\text { formas de publicação, temáticas em voga e } \\
\text { gêneros emergentes; } \\
\text { - Exemplificação dos gêneros da literatura } \\
\text { digital (Ciberpoesia, hiperconto, nanoconto entre } \\
\text { outros), usando, para tanto, o datashow. }\end{array}$ \\
\hline $2^{\circ}$ momento interativo & $\begin{array}{l}\text { - Leitura do HM "Um Estudo em vermelho", de } \\
\text { Marcelo Spalding. } \\
\text { - Socialização e impressões de leitura (Ênfase } \\
\text { aos novos modos de ler na contemporaneidade - } \\
\text { lautoria). }\end{array}$ \\
\hline $3^{\circ}$ momento interativo & $\begin{array}{l}\text { - Leitura do Romance "Um estudo em } \\
\text { vermelho" de Sir. Arthur Conan Doyle. (Leitura } \\
\text { prévia e discussão em sala) }\end{array}$ \\
\hline $4^{\circ}$ momento interativo & $\begin{array}{l}\text { - Divisão da turma em grupos (cada grupo ficará } \\
\text { responsável por apresentar um dos textos } \\
\text { estudados, com vista a estabelecer relações entre } \\
\text { os textos discutidos). }\end{array}$ \\
\hline $5^{\circ}$ momento interativo & $\begin{array}{l}\text { - Estudo do gênero "Resenha" (Estrutura } \\
\text { composicional). }\end{array}$ \\
\hline $6^{\circ}$ momento interativo & $\begin{array}{l}\text { - Leitura de Resenhas na plataforma Skoob, } \\
\text { atentando para as suas composições no ambiente } \\
\text { digital. }\end{array}$ \\
\hline $7^{\circ}$ momento interativo & $\begin{array}{l}\text { - Produção da resenha sobre a obra literária "Um } \\
\text { estudo em vermelho", de Conan Doyle. }\end{array}$ \\
\hline $8^{\circ}$ momento interativo & - Reescrita da resenha produzida. \\
\hline $9^{\circ}$ momento interativo & - Postagem da resenha na rede social Skoob. \\
\hline
\end{tabular}


Visando uma melhor compreensão para o desenvolvimento dessa proposta didática, seguiremos com a descrição dos nove momentos interativos, a saber:

Primeiro momento interativo: O professor deve iniciar as discussões refletindo acerca das redes sociais digitais, as formas de publicação, as redes sociais que os alunos costumam acessar, quais gêneros textuais que são encontrados nestes ambientes virtuais, os tipos de textos publicados, e, por fim, o lugar da literatura nas redes sociais e os gêneros da literatura digital, buscando exemplificá-los, através de sua leitura online elou prints desses gêneros visualizados a partir de um Datashow.

Segundo momento interativo: O professor deverá fazer a apresentação e leitura de um Hiperconto Multissemiótico. Sugerimos o hiperconto "Um estudo em vermelho", de autoria de Marcelo Spalding, jornalista, escritor e idealizador do portal "Literatura Digital" e precursor do movimento em defesa da literatura digital no Brasil. Esse hiperconto utiliza-se de ferramentas tecnológicas para potencializar a narrativa. Mas, é errôneo conceber esse tipo de narrativa digital como um jogo (do tipo competitivo, cuja finalidade sempre é a conquista da vitória), pois, diferentemente, o hiperconto tem em seu cerne outros propósitos, como, por exemplo, a divulgação da literatura digital.

Em "Um estudo em vermelho", a construção do conto pelo lautor se dá a partir das respostas ao e-mail trocado diretamente com o personagem principal o Mr. Dupin. A trama versa na solução de um caso pelo detetive em questão, personagem principal da história, que necessita colher informações da pessoa que solicitou seus serviços, no caso, o próprio lautor, com o intuito de solucionar o caso. Além de chamar atenção para a matéria literária do texto, o professor deve explicitar, também, os novos modos de ler e escrever no ambiente digital.

Terceiro momento interativo: $O$ professor deve iniciar a discussão com a turma, partindo da leitura do primeiro romance do inglês Sir. Conan Doyle, "Um Estudo em Vermelho", que narra o início da parceira entre Sherlock Holmes e Whatson, trabalhando as relações intertextuais presentes entre os gêneros hiperconto e romance. Para tanto, há a necessidade da leitura prévia de alguns capítulos desse romance na sua versão impressa. Em seguida, o professor deve apresentar as semelhanças e diferenças entre os dois gêneros, as estratégias de leitura utilizada para ambos, bem como a experiência em relação aos suportes em que se encontram, no caso do Hiperconto Multissemiótico, do suporte digital, e do romance de Doyle, o livro físico de papel. É importante que o professor chame atenção, durante esta diferenciação, para o potencial hipertextual oferecido pela narrativa do hiperconto devido ao seu caráter rizomático, ao romper com os saberes enciclopédicos (Robin, 2016), permitindo o exercício de diferentes habilidades de leitura que não só aquelas já hegemonizadas no ambiente escolar.

Quarto momento interativo: O professor deverá dividir a turma em grupos, de forma que os componentes de cada grupo se responsabilizem pela apresentação dos dois gêneros em estudo, abordando, principalmente, relações intertextuais outras que não as mencionadas nas discussões anteriores feitas com os alunos.

Quinto momento interativo: Por partirmos da assertiva de que toda escrita exige uma função social, e, no intuito de reforçar os pontos de vista acerca dos gêneros estudados, sugerimos que o professor solicite aos alunos a produção de resenhas para serem postadas (publicadas), posteriormente, na plataforma literária Skoob, uma rede 
colaborativa para leitores, de origem brasileira. Antes da produção escrita, deverão ser estudados os aspectos formais do gênero textual Resenha.

Sexto momento interativo: Para se conhecer o ambiente literário digital da plataforma $S k o o b$ e suas especificidades, serão lidas algumas resenhas postadas nessa plataforma, e, assim, os alunos entenderão as funções comunicativas que devem ser utilizadas na escrita do gênero resenha bem como o suporte digital (lócus físico e/ou virtual que abriga os gêneros) cujo gênero será postado.

Sétimo momento interativo: Este será o momento propriamente dito da produção textual. Após os alunos estudarem os aspectos estruturais do gênero escolhido, deverão produzir a resenha do livro "Um estudo em vermelho", de Conan Doyle.

Oitavo momento interativo: Antes de serem postadas na rede social Skoob, as resenhas serão lidas para turma e apreciadas coletivamente. Os alunos farão a leitura das resenhas uns dos outros e darão sugestões, caso sejam necessárias, antes da postagem definitiva na plataforma. Através desse exercício de reescrita coletiva, os alunos poderão perceber inadequações dos textos produzidos e, se for o caso, corrigi-los.

Nono momento interativo: Em seguida, o professor deve conduzir e estimular os alunos a publicarem as versões finais das resenhas, atentando para as nuances oferecidas pela ambiência digital. Isso porque, segundo Rojo (2015), vivemos em um período chamado de hipermodernidade, no qual as ações como - "curtir, comentar e compartilhar" - ganham destaque nesse tempo, o que justifica a postagem das produções escritas dos alunos, possibilitando que mais usuários da internet conheçam o gênero resenha pelo acesso à plataforma e, por que não dizer, que estes se sintam estimulados a produzir também uma resenha.

Levando em consideração a proposta didática acima apresentada, acreditamos que o professor estabelecerá um diálogo entre a literatura, os gêneros textuais e as possibilidades oferecidas pelo ciberespaço, ambiente tão conhecido pelos alunos, e que podem (e devem) ser aproveitadas na sala de aula, fazendo com que o trabalho com a literatura digital seja prazeroso e significativo.

\section{5 À guisa de conclusão}

Em tempos da web 2.0 (essa rede interativa da internet que se caracteriza pela possibilidade de produção e não somente o acesso à informação), todos os usuários têm a oportunidade de serem produtores, haja vista a quantidade de conteúdo compartilhado através de redes sociais, sites ou web pages.

Nesse contexto, leitores e escritores deparam-se com novos conceitos, novas linguagens, e, sobretudo, com um novo estilo de ler e escrever. Por sua vez, imersa neste universo de mudanças, a literatura também passa a ser repensada, outros estilos tomam forma e ganham destaque, como a literatura digital, entendida como uma possibilidade de potencialização dos gêneros do campo literário, através dos recursos oferecidos pela virtualidade, e passível de ser utilizada no espaço escolar, haja vista a sua aproximação com as práticas de linguagens vivenciadas pelos alunos.

Ao propormos uma sistematização de atividades, que pudessem inserir essa vertente literária na escola, preocupamo-nos em conciliar os vários saberes que a 
circundam, a fim de promover uma aprendizagem significativa para os alunos, bem como a leitura literária tanto de narrativas contemporâneas como Hiperconto Multissemiótico, quanto de romances clássicos em consonância com a produção de textos.

Uma proposta dessa natureza conduz a caminhos traçados para um trabalho inovador a partir da leitura e da produção de textos, mediado por gêneros textuais emergentes do ciberespaço, já que, na atualidade, para transitar neste meio, essas competências já não podem ser as mesmas de antigamente.

\section{Referências}

BUZATO, M. E. K. Letramentos Digitais e Formação de Professores. In: Anais do III Congresso Ibero-Americano Educarede. São Paulo: CENPEC, 2006. p. 81-86.

CHARTIER, R. A aventura do livro do leitor ao navegador: conversações com Jean Lebrun. 1. reimpressão. Tradução de Reginaldo Carmello Corrêa de Moraes. São Paulo: Imprensa Oficial do Estado de São Paulo/Editora UNESP, 1998.

Os Desafios da Escrita. São Paulo: UNESP, 2002.

COSCARELLI, C.V. (org.). Tecnologias para Aprender. São Paulo: Parábola Editorial, 2016.

COSSON, R. Círculos de Leitura e Letramento Literário. São Paulo: Contexto, 2014.

Letramento literário: teoria e prática. São Paulo: Contexto, 2006.

GOMES, C. M. Leitura e Estudos Culturais. In: Revista Brasileira de Literatura Comparada: Rio de Janeiro: ABRALIC, v.1, n.16, 2010. Disponível em < http://www.abralic.org.br/downloads/revistas/1415576014.pdf > Acesso em agosto de 2017.

KLEIMAN, A. B. Os significados do Letramento: uma nova perspectiva sobre a prática social da escrita. Campinas, SP: Mercado das Letras, 1995.

MESTRE, A. I. B. Literatura 2.0: para uma cartografia da narrativa digital. Tese (Doutorado) - Curso de Comunicação, Cultura e Artes, Universidade do Algarve, Algarve, 2017.

ROBIN, R. A Memória Saturada. Tradução de Cristiane Dias e Greciely Costa. Campinas - SP: Editora da Unicamp, 2016.

ROJO, R. Pedagogia dos Multiletramentos: diversidade cultural e de linguagens na escola. In: MOURA, E; ROJO, R (orgs). In: Multiletramentos na Escola. Roxane Rojo e Eduardo Moura (Orgs.), São Paulo: Parábola editorial, 2012.

. et al (Org.). Escola Conectada: os multiletramentos e as TICS. São Paulo:

Parábola, 2013. 
.; BARBOSA,J.P. Hipermodernidade, Multiletramentos e Gêneros Discursivos. São Paulo: Parábola, 2015.

SALES. C; AZEVEDO. W. A Literatura Digital e sua Escritura Expandida: uma reflexão sobre a obra Volta ao Fim. In: Revista Brasileira de Literatura Comparada. Rio de Janeiro: ABRALIC, v. 1, n. 20, 2012.

SANTAELLA, L. O novo estatuto do texto nos ambientes de hipermídia. In: SIGNORINI. I. (org). [Re]discutir texto, gênero e discurso. São Paulo: Parábola Editorial, 2008.

SILVA, A.P.D. Aspectos do conto e do romance da atualidade: problemas de ordem teórico-conceitual. In: SILVA, A.P.D. (Org.). O conto e o romance contemporâneo na perspectiva das literaturas pós-autônomas. Campina Grande: Eduepb, 2016.

O Ensino de Literatura Hoje: da crise do conceito à noção de escritas. Campina Grande: EDUEPB, 2016.

SOARES, M. Letramento: um tema em três gêneros. 3. ed. 1 reimp. Belo Horizonte: Autêntica, Editora, 2012.

- Novas Práticas de Leitura e Escrita: letramento na cibercultura. Revista Educação e Sociedade: Campinas, v.23, n.81, p.143-160, dez. 2002. Disponível em http://www.cedes.unicamp.br.

SPALDING, M. Um Estudo em Vermelho, 2009. Disponível em < < http://www.hiperconto.com.br/estudoemvermelho/ > Acesso em 10 maio de 2018.

. Alice do livro impresso ao e-book: adaptação de Alice no País das Maravilhas e de através do espelho para ipad. Tese (Doutorado). Universidade Federal do Rio Grande do Sul. Instituto de Letras. Programa de Pós-Graduação em Letras, 2012.

Recebido em 19 de outubro de 2018

Aceito em 22 de novembro de 2018 